\title{
PERSPECTIVA DA GESTÃO DO CONHECIMENTO E A EDUCAÇÃO DE JOVENS E ADULTOS: DESAFIOS E POSSIBILIDADES
}

http://dx.doi.org/10.5902/2318133825545

\author{
Antonio Amorim \\ Universidade do Estado da Bahia, Brasil.
}

\author{
Aldaíce Damasceno Rocha \\ Centro Estadual de Educação Magalhães Netto, Brasil
}

\author{
Alfredo Eurico da Matta \\ Universidade do Estado da Bahia, Brasil.
}

\section{Resumo}

Este artigo objetiva identificar o papel que a gestão do conhecimento ocupa na educação de jovens e adultos e as práticas de gestão escolar que estão correlacionadas com as de gestão do conhecimento. Os instrumentos utilizados para coleta e análise dos dados foram à entrevista semiestruturada e a aplicação de questionário. Os resultados apontaram para a necessidade de consolidação de práticas compatíveis com o modelo teórico da gestão do conhecimento, apresentando a possibilidade de usar técnicas e ferramentas com o intuito de efetivar melhorias no desenvolvimento educativo.

Palavras-chave: educação de jovens e adultos, gestão do conhecimento, gestão escolar, gestão inovadora dos saberes.

\section{KNOWLEDGE MANAGEMENT PERSPECTIVE ON ADULT AND YOUTH EDUCATION: CHALLENGES AND POSSIBILITIES}

\begin{abstract}
This article aims to identify the role of knowledge management in adult and youth education and school management practices that are correlated with knowledge management. The instruments used for data collection and analysis were the semi-structured interview and questionnaires. As a result, were identified practices compatible with the theoretical model of knowledge management, introducing using techniques and tools in order to effect improvements in educational devealopment.

Key-words: adult and youth education, knowledge management, school management, innovative management of knowledge.
\end{abstract}




\section{Introdução}

este artigo estuda-se o papel que a gestão do conhecimento ocupa na educação de jovens e adultos e as práticas de gestão escolar que estão relacionadas com a gestão do conhecimento, tomando-se como referência o Centro Estadual de Educação Magalhães Netto - CEA -, localizado em Salvador/BA. Pretende-se compreender o que é a gestão do conhecimento e qual é o papel que ocupa na Educação de Jovens e Adultos para investigar se a instituição de ensino focalizada adota práticas de gestão compatíveis com a gestão do conhecimento.

No cruzamento das informações deve-se observar se a gestão do conhecimento pode oferecer meios para aperfeiçoar a gestão da EJA. Considera-se que o acesso à educação, à apropriação das competências no processo de ensino e aprendizagem e o desenvolvimento da capacidade de gestão baseada no conhecimento podem transformar e contribuir para a compreensão do sujeito sobre o mundo, ampliando a consciência e a atuação em sua transformação. Partindo deste pressuposto, acredita-se que este processo gestor pode favorecer a construção de uma gestão inovadora dos saberes da EJA, contribuindo para a melhoria da qualidade de ensino ofertada.

O conhecimento é um instrumento que habilita para o sucesso, tanto nas dimensões das organizações, quanto na questão do desenvolvimento humano. Tudo o que se faz, se pensa e se constrói está indissociável à idéia de uma forma de conhecimento ou de construção de novos saberes. Essa é a dinâmica da sociedade contemporânea, uma sociedade que vive na era da informação e do conhecimento. A gestão do conhecimento é, no momento, uma das fontes de qualificação do sujeito individual e coletivo. Informação e conhecimento sozinhos não resolvem todos os problemas socioeconômicos e culturais, contudo, contribuem para contornar as desigualdades da sociedade (Daft, 2002).

Haja vista que, com a globalização, comunicação ágil e interatividade em todos os setores, muito do conteúdo das informações se perdem. É preciso, então, planejar e estudar uma forma de controle, buscar acessibilidade a esta informação e gerenciamento integrado para alcançar os objetivos desejados. Esse processo de gerenciamento é conhecido como a gestão do conhecimento, um tipo de sistematização, articulada ou intencional, para gerar, codificar, disseminar e apropriar o conhecimento a fim de alcançar a excelência organizacional. $O$ conhecimento aqui é compreendido como sendo a informação interpretada, correlacionada e integrada às experiências de impactos no meio educacional, especificamente à educação de jovens e adultos.

Entende-se que a dimensão da gestão do conhecimento auxilia na transformação dos processos da escola - micro e macroprocessos: gestão escolar baseada na gestão de processos de conhecimento; gestão da sala de aula; gestão do currículo; concepção do projeto de avaliação institucional baseada no conhecimento. Dessa forma a gestão do conhecimento é usada no sentido de melhorar os processos das instituições de ensino, identificando como auxiliá-los, ou seja, que formas, técnicas ou ferramentas a gestão do conhecimento oferece para se aliar à estratégia de melhorias propostas ou desenvolvidas para a gestão da educação de jovens e adultos, focando em novos aprendizados, saberes e formas de adquirir conhecimento. Assim sendo, será objeto desse estudo as possíveis estratégias de gestão do conhecimento utilizadas pela gestão da EJA de uma escola pública estadual voltada para jovens e adultos, localizada em Salvador, Bahia. 
No decorrer deste artigo será analisada a fundamentação teórica sobre a gestão do conhecimento, funcionamento e formas de atuação, a educação de jovens e adultos e a gestão dos saberes, e, por último, o resultado da análise e coleta de dados realizada durante o trabalho. Além disso, serão levantadas as sugestões para a melhoria do sistema de ensino que trabalha com as classes da EJA, considerando a gestão dos saberes.

Para tanto, será utilizado o modelo de gestão do conhecimento proposto por Nonaka e Takeuchi (1997), Davenport e Prusak (1998) e Probst, Raub e Romhardt (2002), para investigar quais das práticas utilizadas no Centro Estadual de Educação Magalhães Netto seriam adequadas ao processo de construção dos diferentes saberes da EJA.

\section{Percurso metodológico}

A partir da problemática e dos objetivos do estudo definiu-se a abordagem qualitativa como sendo a mais adequada para este processo investigativo. Considera-se $o$ processo de instrumentalização da pesquisa de campo como sendo parte integrante deste processo. Optou-se por esta abordagem, pois, a flexibilidade constitui-se como marca no que se refere às técnicas de coleta de dados, bem como à sua interpretação, no entanto,

é preciso esclarecer, antes de mais nada, que as chamadas metodologias qualitativas privilegiam, de modo geral, da análise de micro processos, através do estudo das ações sociais individuais e grupais. Realizando um exame intensivo dos dados, tanto em amplitude quanto em profundidade, os métodos qualitativos tratam as unidades sociais investigadas como totalidades que desafiam o pesquisador. (Martins, 2004, p. 292)

A pesquisa qualitativa, segundo Richardson (1999), pode ser ainda caracterizada como sendo a tentativa de uma compreensão detalhada dos significados e características situacionais apresentadas pelos entrevistados em lugar da produção de medidas quantitativas de características ou comportamento. Pela pesquisa de campo procurou-se buscar informações junto à população analisada, considerando o encontro direto do pesquisador com a fonte dos dados e das informações (Gonsalves, 2001).

Para a amostragem da investigação foram escolhidos gestores, docentes, alunos de EJA da escola. Os instrumentos utilizados foram à entrevista semiestruturada e a construção de relatórios específicos de observação do ambiente investigado. O roteiro de entrevista foi simples, voltado para as questões do conhecimento e da interação da comunidade escolar neste processo, abordando a temática sobre gestão do conhecimento, gestão escolar e a prática do educador e do aluno na EJA. Depois de coletar as contribuições dos participantes foi possível analisar o conjunto dos dados e das informações para consolidar o trabalho de pesquisa de campo.

Para a coleta e a análise dos dados foi elaborado um modelo de explicação utilizando-se as dimensões da gestão referenciadas ao modelo teórico de gestão do conhecimento aqui apresentado e dividido em três etapas: aquisição e geração do conhecimento; disseminação, compartilhamento e transferência do conhecimento; codificação do conhecimento ou construção da memória. Este modelo buscou investigar se práticas de gestão do conhecimento são desenvolvidas pela instituição de ensino e quais práticas utilizadas se adequariam à caracterização de prática de gestão do conhecimento. 


\section{Gestão do conhecimento: conceitos e fundamentos}

Para abordar a gestão do conhecimento em seus fundamentos básicos considera-se que seja preciso analisar os conceitos elementares, incluindo o próprio conceito de conhecimento, com o objetivo de distanciar a discussão das referências do senso comum. Drucker (1999) conceitua conhecimento como sendo a informação eficaz em ação, focalizada em resultados. Nonaka e Takeuchi (1997, p. 63) compreendem que "o conhecimento, ao contrário da informação, diz respeito a crenças e compromissos". Asseveram, ainda, que o conhecimento é função de uma atitude, perspectiva ou intenção específica e, ao contrário da informação, o conhecimento está relacionado à ação. Os autores consideram o conhecimento como sendo um processo humano dinâmico de justificar a crença pessoal, sendo específico ao contexto relacional.

Segundo Nonaka e Takeuchi (1997) é necessário que se crie conhecimento organizacional, impedindo que o conhecimento seja mantido apenas no âmbito individual. Afirma que as organizações só aprendem por meio de indivíduos que aprendem, mas a aprendizagem individual não garante a aprendizagem organizacional. O processo de gerir eficientemente o conhecimento está, segundo os autores, diretamente relacionado com a aprendizagem organizacional, uma vez que a mesma envolve aprender e ter domínio sobre algum tipo de conhecimento. Tomando esta acepção pode-se inferir que todas as atividades realizadas nas organizações passam pelo processo de aprendizagem. Todavia, o processo de aprendizagem não implica, necessariamente, na existência de sua gestão. O conhecimento que um colaborador possui, por exemplo, pertence a ele e se não for disseminado e nem usado pela organização, passa a ser, apenas, um conhecimento individual (Dibella; Nevis, 1999). A aprendizagem organizacional deve ser um processo orientado para alguma finalidade, ou seja, as pessoas devem utilizar o que aprendem para criar e manter um diferencial de qualidade nas suas organizações.

Partindo da premissa de que as pessoas podem saber mais do que são capazes de dizer, Polanyi (2000) desenvolveu um novo conceito de conhecimento, distinguindo conhecimento tácito: pessoal, especifico ao contexto, e, assim, difícil de ser formulado e comunicado, e, conhecimento explícito: codificado, transmissível em linguagem formal e sistemática, observando que os seres humanos adquirem conhecimentos criando e organizando, ativamente, as suas próprias experiências. Segundo Nonaka e Takeuchi (1997, p. 66), o conhecimento tácito é criado "aqui e agora," num contexto prático e especifico, sendo que o seu compartilhamento acontece pela comunicação, constituindose num processo análogo que exige uma espécie de "processamento simultâneo" das complexidades dos problemas compartilhados pelos indivíduos, enquanto que 0 conhecimento explícito lida com acontecimentos passados ou objetos.

Conforme os autores, do ponto de vista de sua formalização, o conhecimento pode ser tácito ou explícito, sendo considerado tácito quando é parte intrínseca do estoque pessoal de um indivíduo - know-how, crenças, percepções -, contudo não é facilmente codificável ou acessível a outros; passando a ser explícito quando sua natureza é objetiva ou pode ser representada pela comunicação.

A conversão do conhecimento tácito - explícito - tácito, em contínuo processo espiral de criação - transferência - inovação, é o principal objeto de estudo da gestão do conhecimento, conforme apresenta Nonaka e Takeuchi (1997). Sob a perspectiva da 
prática profissional o gestor de conhecimentos se ocupa dos processos e das tecnologias para aquisição, via captação ou produção, organização, por codificação, registro, seleção, análise e socialização.

Ao optarem por gerir seus ativos intelectuais as organizações da nova economia reconhecem ser o conhecimento a única vantagem competitiva, sustentável ao longo do tempo, devido a seu alto poder multiplicador e ao seu grande potencial gerador de resultados positivos. Para que o conhecimento organizacional seja criado, segundo aponta os autores, é preciso converter os conhecimentos tácito e explícito dos indivíduos em conhecimento amplificado na organização.

A gestão do conhecimento é pautada na gestão das atividades e dos processos que promovem o conhecimento para aumentar a competitividade pelo uso e pelo desenvolvimento de fontes de conhecimento individuais e coletivas. Tudo isso com o objetivo de buscar a melhoria da produtividade por meio da gestão de processos que aperfeiçoem os ciclos do conhecimento organizacional (Zheng; Yang; Mclean, 2010). Isso vem com autoridade para melhorar os processos das organizações, efetuando análises sobre os fatos nelas ocorridos, para que estes possam servir de base para a tomada de decisões. Salienta-se, também, a busca pela qualidade profissional gerando grandes resultados ao capital intelectual de uma organização.

\section{Conhecimento e gestão dos saberes na EJA}

É inegável que uma escola bem organizada e gerida cria e assegura condições pedagógico-didáticas, organizacionais e operacionais que propiciam o bom desempenho da comunidade escolar e o sucesso na aprendizagem. O modo como a escola funciona suas práticas de organização e de gestão - faz diferença em relação aos resultados escolares dos alunos (Libaneo, 2004).

De acordo com a LDB, a EJA passou a ser uma modalidade de educação básica nas etapas de ensino fundamental e médio que tem como fundamento dar oportunidades de escolarização e proporcionar uma educação que desenvolva a criticidade e a inserção no contexto social atual (Brasil, 1996). Desse modo, os jovens e adultos que não tiveram oportunidades de estudar na idade certa e precisaram voltar à rede de ensino - muitos deles trabalhadores que participam da garantia da sobrevivência de suas famílias trazem em suas relações sociais, culturais e afetivas especificidades de conhecimento, memória, religiosidade e de política. Essas dimensões devem, então, ser incorporadas ao saber escolar. Diante disso, a escola pode assumir o papel de ser mais um agente de aprendizagem, além de tantos outros espaços já incorporados à prática cotidiana desses sujeitos.

A atual sociedade do conhecimento se utiliza muito do pensamento sistêmico. Daft (2002) afirma que as organizações são sistemas interagindo em várias partes. Visto desta forma pode-se dizer que o mundo é um sistema, a vida é um sistema, a educação é um sistema e a educação de jovens e adultos, particularmente, é um sistema. A gestão do conhecimento e a educação de jovens e adultos se inserem, então, no contexto da Teoria Sistêmica das Organizações. Desta maneira a educação é um processo que conduz ao treinamento da mente para buscar as novas conquistas sociais. Trata-se de um sistema amplo, complexo, organizacional, que parte da ânsia incontida do ser humano pelo aperfeiçoamento; sendo visto como um imperativo do tempo-espaço social. 
Nesse caso, se o conhecimento sobre gestão é a entrada de um processo de melhoria na qualidade de ensino ofertado, o conhecimento sobre a EJA deve ser gerido para que o resultado seja alcançado. Esta afirmação evidencia a relação entre o conhecimento e a educação de jovens e adultos, bem como a importância de bem geri-lo. O presente estudo feito acerca da relação entre gestão do conhecimento e EJA, realizado com integrantes da comunidade escolar do Centro Estadual de Educação Magalhães Netto - CEA - pode observar que as melhores atitudes de gestão estão direta e positivamente relacionadas aos grupos com maior conhecimento sobre esta modalidade de ensino, confirmando a importância que tem a equipe pedagógica dos programas de EJA, para trabalhar o conhecimento que pretende disseminar junto à comunidade escolar. A importância dada à informação e ao conhecimento na EJA deve implicar, consequentemente, numa boa gestão deste processo educativo.

Pode-se afirmar que a sala de aula é o espaço de encontro entre alunos, professores e conhecimento. Vínculos de amizade, cooperação e confiança se constroem e se consolidam neste espaço dando vida ao processo de ensino aprendizagem. Antes mesmo de ter acesso a conhecimentos considerados científicos o indivíduo, empiricamente, constrói explicações para os fenômenos naturais, sociais e culturais. Estes saberes particulares servem de acesso a outros novos conhecimentos. Assim sendo, cada aluno é um sujeito repleto de saberes individuais, coletivos, múltiplos, oriundos da interação com o meio físico, familiar, da experiência com o trabalho, do agir e dos papéis sociais que cada um representa na vida. Sob este enfoque a sala de aula pode ser caracterizada por ser pulsante, viva e dinâmica. Por conseguinte, o espaço da sala de aula emana vivência, experimentação, ação e construção do conhecimento. A adoção de ferramentas e de técnicas inerentes à gestão do conhecimento, num ambiente de EJA, pode fortalecer a relação entre alunos, professores e a gestão escolar. Portanto, a inovação na gestão da escola é um desafio que se está impondo aos gestores desta modalidade de ensino.

Entende-se que as transformações e a complexidade do mundo atual provocam rupturas na organização do modo de produção, pondo em cheque o trabalho, fazendo emergir o conhecimento como categoria central das novas relações e da vida social. A escola, enquanto instituição complexa, tem como função social a socialização dos saberes para a formação integral do indivíduo. Destarte, é necessária uma formação continuada para que o gestor escolar tenha discernimento ao tomar uma posição ou mesmo implantar ações pedagógicas, administrativas, financeiras ou realizar algum investimento no capital intelectual da comunidade escolar para a melhoria da qualidade de seus processos educativos.

Após conhecer algumas alternativas de uso da gestão do conhecimento vale salientar a possibilidade de qualidade trazida para as organizações. Nas instituições de desenvolvimento de educação o termo qualidade está inserido com força em todos os processos existentes, desde planejamento, produção, aplicação e avaliação dos projetos. Os fatores que abrangem e dão possibilidade a tais necessidades das instituições de educação de jovens e adultos são as técnicas de gestão do conhecimento aliadas às estratégias de contextualização, valorização e incorporação dos saberes prévios dos membros da equipe escolar. 
A partir da informação, do conhecimento e da percepção da EJA como segmento da educação básica espera-se que a visão acerca desta modalidade de ensino seja alargada, os comportamentos, as ações e as atitudes sejam ressignificados.

\section{Resultados: possibilidades abertas pelo desenvolvimento do conhecimento e o uso da tecnologia digital na EJA}

O avanço da tecnologia digital leva a entender que alguns aportes simples e pertencentes ao alcance das escolas e dos membros da comunidade escolar poderiam melhorar substancialmente as questões de gestão escolar da EJA.

A presença de um simples gestor de cadastro do pessoal da escola permitiria melhorar muito a gestão da prática destes sujeitos à medida que mesmo sem poder contratar, dispensar, promover ou remanejar professores e funcionários, o gestor teria melhor conhecimento e entendimento de seu pessoal e de suas potencialidades ao utilizar este cadastro. Isso implica em reconhecer que dar às escolas a prática e a estrutura de bases de dados poderia, imediatamente, reduzir os custos e melhorar a gestão, ainda que o gestor permanecesse sem autoridade. Ao menos com maior controle sobre as informações sobre aqueles que trabalham na escola, assim como de suas designações de responsabilidade, poderia elevar o nível de comprometimento do gestor com sua unidade escolar.

Se a gestão pedagógica já foi analisada como satisfatória, uma vez pudesse a cultura escolar brasileira ter nos computadores parceiros mais frequentes e presentes nas escolas, em particular aquelas do interior do país, teríamos resultados superiormente melhores que os já satisfatórios que obtivemos.

Em relação ao desenvolvimento da gestão do conhecimento destacamos que a adoção mais relevante, continuada e sustentável dos computadores pela gestão escolar de imediato elevaria todos os níveis de registro, resultados e reuso do conhecimento produzido. De fato, este incremento seria de potencial, pois aí os docentes do colégio deveriam estar preparados para estes usos.

A habilitação dos gestores e professores das escolas no uso da rede mundial de computadores, além de conhecimento que necessitam adquirir sobre como utilizar estes artefatos digitais na gestão da escola, certamente, ajudaria bastante na gestão da geração e da aquisição de conhecimento. Por outro lado, ao considerar a importância do conhecimento e da gestão da memória institucional e cultural dos colégios e das escolas públicas se deve, em conjunto, entender como a operação de bases de dados e sistemas fortalecerá o atendimento desta gestão da memória e da cultura que são demandadas. Assinalamos ser o desenvolvimento da informática nas escolas parte do processo de valorização da gestão escolar.

A análise dos dados e das informações coletados no ambiente da investigação demonstraram, ainda, que alguns dos requisitos apresentados por Nonaka e Takeuchi (1997) são necessários à gestão e à criação do conhecimento, não ocorrendo em determinados contextos e ambientes estudados, e que se comportam de maneira um pouco diferente para a modalidade de jovens e adultos.

Os relatórios construídos junto às observações das atividades desenvolvidas por alunos, professores e gestores da escola permitiram inferir que as práticas simples de gestão podem ser adotadas pela comunidade escolar, sendo compatíveis com as 
propostas que são oriundas do modelo teórico de gestão do conhecimento. Isso consolidaria a perspectiva de construção de uma gestão inovadora dos saberes e da melhoria na qualidade do ensino ofertado nas classes da EJA, tendo o controle da frequência escolar, a integração da escola com a sociedade, ampliação da dinâmica organizacional dos alunos, da proposta escolar contextualizada, do monitoramento da aprendizagem, da inovação pedagógica e da consolidação do planejamento da escolar.

A dimensão tácita do conhecimento, observada por Nonaka e Takeuchi (1997), prevalece na instituição de ensino, o que exige um forte processo de socialização para que o conhecimento seja desenvolvido (Fonseca, 2005). O autor assevera que os diretores de escolas não têm autoridade para contratar, dispensar, promover ou remanejar professores e funcionários, portanto, talvez, sintam-se, em maior ou menor grau, desincumbidos ou impedidos de quaisquer procedimentos no sentido de desenvolver, avaliar, sensibilizar, estimular e mobilizar as pessoas no ambiente de trabalho, seguindo um programa de ações em tal ambiente. Isto é um sério entrave que ocorre a qualquer pretensão de gestão do conhecimento, como defendem Davenport e Prusak (1999) e Terra (2001), já que as pessoas são o seu ponto de partida.

Ficou evidente que a gestão pedagógica é aquela que mais atende ao cumprimento das três etapas da gestão do conhecimento: atenderam às etapas de aquisição, de disseminação e de registro. Isto talvez se deva ao fato de que a gestão pedagógica esteja no centro das atividades de qualquer escola, inclusive cumprindo exigências legais e determinações dos órgãos fiscalizadores do ensino.

Os fatores desfavoráveis ao registro do conhecimento, que foram evidenciados na escola, são: a cultura organizacional, em que as pessoas não estão habituadas e não observam a importância de registrar, de forma bem detalhada, as experiências, os processos, os projetos, as avaliações e as ideias. Isso, com certeza, poderia permitir a consolidação de um melhor desenvolvimento dos processos de externalização, de combinação e de internalização do conhecimento (Nonaka; Takeuchi, 1997); e, a falta de tempo, ocasionada por sobrecarga de trabalho (Probst; Raub; Romhardt, 2002).

A carência de registros do conhecimento e construção da memória da instituição de ensino dificulta a aprendizagem organizacional (Lemos, 1999; Alves, 2005) e o maior compartilhamento e reuso do conhecimento organizacional, do conhecimento individual e das lições aprendidas na execução das tarefas da organização (Orosco et al., 2015).

Fatores negativos para a disseminação do conhecimento podem ser apontados: pela falta de reconhecimento e de valorização do conhecimento individual (Stewart, 2002); pela ausência de tempo livre da equipe pedagógica para socialização do conhecimento (Nonaka; Takeuchi, 1997; Davenport; Prusak,1999). Quanto à disseminação, compartilhamento e transferência do conhecimento, mesmo que não tenham ocorrido no nível necessário, verificou-se que atingiram boa parte das práticas. Vale salientar um ponto comum analisado nas entrevistas com os integrantes da comunidade escolar que diz respeito à falta de práticas de valorização e de reconhecimento do trabalho e do esforço dos professores e demais profissionais da escola, no sentido de reforçar ações voltadas para a melhoria da qualidade do ensino, dinâmicas para desenvolver equipes e lideranças, elevando a motivação e a autoestima dos profissionais, com a mediação dos conflitos existentes. 
Consideram-se como sendo os fatores positivos à orientação para a melhoria do processo (Davenport; Prusak, 1999), a habilidade do gestor para organizar e trabalhar equipe com eficácia e a habilidade dessas equipes para aprender fazendo, ou seja, para incorporar os conhecimentos obtidos pelas suas experiências (Nonaka; Takeuchi, 1997). Já em relação à metodologia de ensino, considera-se que esta deve ser baseada em projetos pedagógicos com metas a serem alcançadas no curto prazo. Os fatores mais favoráveis à aquisição e a geração de conhecimento, na instituição pesquisada, foram os seguintes: atividades integradoras proporcionadas pelos projetos pedagógicos multidisciplinares - as quais promovem a socialização do conhecimento (Probst; Raub; Romhardt, 2002; Stewart, 2002) - e o aprendizado com as próprias experiências e com as experiências em melhores práticas de outrem (Garvin, 2000).

Quanto à aquisição e a geração de conhecimento, boa parte dos docentes teve a oportunidade de participar de programas de capacitação na área específica de atuação com investimentos próprios, entretanto, a maioria não participou de formação continuada em EJA, atividade esta que foi promovida pelos órgãos centrais de ensino. Já ocorreram em outras gestões, por iniciativa da escola, ações de formação continuada com base na identificação de necessidades dos docentes e demais profissionais em relação aos conhecimentos, habilidades e atitudes requeridos para o fortalecimento da prática pedagógica da EJA. Em se tratando da atuação dos dirigentes escolares foi observado que todos têm grande habilidade em se relacionar, desenvolvem a experiência gestora há muitos anos, inclusive, nas classes da EJA. Isto facilitou o desenvolvimento das relações da equipe gestora com a comunidade escolar e local.

Observa-se, de acordo com os conceitos de DiBella e Nevis (1999), que a aprendizagem, na instituição de ensino, acontece, geralmente, com as próprias experiências no desenvolvimento de atividades que ajudam a aprender fazendo, seja em práticas individuais ou coletivas: estilo de aprendizagem por correção. Isso ocorreu também a partir de experiências, das melhores práticas alheias, pela leitura de livros e revistas, sites da Internet: estilo de aprendizagem por adaptação. Professores e supervisores afirmaram dar importância à leitura de revistas pedagógicas e a efetivação de consultas em sites educacionais, na Internet, sempre à procura de exemplos de experiências bem-sucedidas. Pode-se afirmar que estas aprendizagens ocorrem sempre que uma organização faz mudanças incrementais ou aperfeiçoamentos no conhecimento adquirido externamente (Dibella; Nevis, 1999).

Pode-se observar que a escola possui momentos específicos para a disseminação, compartilhamento e a transferência de conhecimento. Tendo espaço adequado auditório, laboratório de informática, biblioteca - e calendário de reuniões periódicas. A realização de projetos que permitem a interação entre professores, de diversas áreas, de atividades diversificadas dentro e fora da escola. Quanto à troca de experiências o compartilhamento do conhecimento na escola acontece de forma interativa entre um professor e outro, porém, nunca na coletividade, prova disso é o fato de os entrevistados terem tido mais facilidade em relatar alguma coisa que tenham ensinado e uma grande dificuldade para lembrar algo que tivessem aprendido com os colegas.

Percebe-se que há menos importância na aprendizagem coletiva. As instalações, o mobiliário e os equipamentos estão bem cuidados e conservados, atestando que houve disseminação do conhecimento. Entende-se que o desenvolvimento de vários projetos é, 
por si só, um modo de disseminar o conhecimento. As transferências de conhecimento são espontâneas e informais e também ocorrem pela socialização do mesmo, pelo aprender fazendo, com o envolvimento dos vários segmentos da escola, nas parcerias realizadas. Podem ser citados projetos desenvolvidos pela escola, recentemente, como por exemplo: Feira de Economia Solidária e Empreendedorismo, Consciência negra: sabores e saberes; Projeto água, jornal CEA em ação, Projeto de leitura e escrita, atendimento a um público jovem e adulto com necessidades educacionais especiais no turno diurno.

Do ponto de vista da gestão do conhecimento, o registro do mesmo ou da construção da memória é o aspecto mais deficiente do Colégio. Os registros realizados por parte da direção atendem, apenas, às exigências burocráticas e não servem para instruir as ações no âmbito de gestão. A interessante e significativa experiência da atual gestão e os conhecimentos que ela proporcionou se não forem registradas, ficarão indisponíveis com a saída dessas pessoas da gestão escolar.

A análise das entrevistas deixa patente o fato de que não existe dedicação ou esforço para o registro do conhecimento. Os variados projetos e as diversas atividades que tem ocorrido na escola, todos eles geradores de conhecimentos, não foram adequadamente registrados, de maneira que pudessem servir de base para novas e mais abrangentes formas de atuação. Constam imagens fotográficas de eventos socioculturais realizados na escola e alguns arquivos de projetos estanques, geralmente individualizados na pessoa do coordenador pedagógico ou de um professor. A escola procede ao registro de dados exigidos pelo Censo Escolar, contudo, não consegue transformá-los em informação para uso interno. Não são realizadas práticas de organização e de atualização da documentação, da escrituração, dos registros dos alunos, dos diários de classe, das estatísticas, da legislação, entre outros, para tornar o atendimento mais ágil à comunidade escolar e ao sistema de ensino. Ocorre, às vezes, perda de dados e de registros de notas de alunos egressos, por estes ficarem no arquivo permanente. São feitas atas das reuniões de Conselho de Classe, do Colegiado Escolar, mas são registros em sumários, sendo que essas reuniões apenas referendam as ações da gestão escolar. Há outra forma de planejamento coletivo e cooperativo observada nas propostas de projetos pedagógicos, mas são registros incompletos.

A experiência descrita apresentou a convergência entre gestão do conhecimento e a gestão de EJA. As práticas colaborativas que se concentram no tripé pessoas, processos e tecnologia. Asseverando que os papéis do gestor e dos professores se assemelham no que concerne ao desenvolvimento de ambiente propício ao compartilhamento de informações e experiências, à facilitação dos processos de conhecer e aprender e ao norteamento dos esforços, havendo a necessidade de liderança e de coordenação das atividades, na direção da efetivação de objetivos, onde cada participante, tenha previamente aderido ao contrato estabelecido com o grupo e consigo mesmo.

No tocante à tecnologia pode ser utilizada como elemento facilitador, enquanto na assimilação do conhecimento deve-se trabalhar a construção de sentido a partir das diferentes áreas de formação e experiência profissional, sendo tal diversidade uma fonte de enriquecimento do processo de ensino aprendizagem. O conhecimento tácito, 
representado pelo intercâmbio com especialistas e pela troca entre os pares, se mostrou como sendo, para os alunos, um estímulo mais forte que o conhecimento explícito disponibilizado nas classes da EJA.

\section{Considerações finais}

Com o estudo realizado para o desenvolvimento do presente artigo concluiu-se que a gestão do conhecimento, com suas técnicas e ferramentas, representa uma alternativa na busca de melhorias contínuas nos processos organizacionais, a exemplo da EJA, que com suas especificidades e seus processos complexos necessitam estar em constante atualização para garantir que o processo de ensino aprendizagem esteja adequado aos objetivos almejados.

O modelo de análise utilizado nesta pesquisa, embora limitado a um estudo de uma escola, comprovou que os princípios da gestão do conhecimento também podem ser aplicados em organizações de ensino. A análise dos dados obtidos permitiu alcançar os objetivos deste artigo: identificar o papel ocupado pela gestão do conhecimento na Educação de Jovens e Adultos e as práticas de gestão escolar correlacionadas à gestão do conhecimento existentes no Centro Estadual de Educação Magalhães Netto.

Esta pesquisa apresenta dois resultados principais: sugere a realização de práticas que favoreçam a gestão e à criação de novos conhecimentos nos programas de educação de jovens e adultos, sendo que estes programas têm muito a melhorar sua efetividade com a adoção de requisitos conceituais já divulgados pela teoria da criação do conhecimento e aqui traduzidos para a realidade da EJA. Como sugestão entende-se que os programas podem realizar eventos que propiciem o compartilhamento de conhecimento e de experiências, fazer uso de bases de dados, relatórios e instrumentos que possibilitem armazenar conhecimento; realizar atividades práticas ensinadas em palestras, aulas, oficinas, projetos, para incorporar o conhecimento tácito de maneira explícita, promover o trabalho em grupos multidisciplinares, dentre outros. Trabalhar a construção de uma cultura organizacional favorável à criação do conhecimento e explorar as ambiguidades e a redundâncias dos temas também podem favorecer a gestão e à criação de novos conhecimentos, entretanto, de maneira intencional, não intuitiva, eventual ou aleatória, como tem acontecido.

Entende-se que para permitir que o conhecimento circule em todas as esferas a escola necessita transformar antigas estruturas, reconstruir valores e reorientar suas ações. Implantar a gestão do conhecimento no ambiente escolar implica na mudança de aspectos da própria cultura organizacional como, por exemplo, o compartilhamento de seus conhecimentos e a adoção de postura reflexiva e crítica diante dos obstáculos e desafios que se interpõem na construção de uma EJA de qualidade.

Destarte, considera-se que a gestão do conhecimento eficaz só ocorrerá mediante uma mudança significativa, seja comportamental, cultural ou organizacional. Por isso, necessita melhor compreender e considerar os sujeitos partícipes e ativos que estão, permanentemente, construindo sentidos para as informações que encontram. Petrash (1996) afirma que é necessário fazer o possível para ter a informação certa, para a pessoa certa, no tempo certo e no formato adequado para a conveniente tomada de decisões. 
Finalmente espera-se que este artigo possa contribuir para a reflexão sobre a gestão do conhecimento como sendo um elemento aglutinador de ações que promovam à geração, o armazenamento, a disseminação e o compartilhamento do conhecimento nas instituições educacionais, possibilitando a reflexão acerca do conhecimento e da gestão do conhecimento e dos saberes na educação de jovens e adultos para permear, tanto a problemática acerca da geração do conhecimento em situação de ensino aprendizagem, quanto às estratégias de gestão baseadas no conhecimento.

\section{Referências}

ALVES, Andréa T. Gestão do conhecimento: o desafio da instituição de ensino superior privada. Pedro Leopoldo: Faculdade Pedro Leopoldo, 2005. 151f. Dissertação (mestrado em Administração). Faculdade Pedro Leopoldo.

AMORIM, Antonio. Escola: uma instituição social complexa e plural. São Paulo: Viena, 2007.

BRASIL. Lei n. 9.394, de 20 de dezembro de 1996. Lei de Diretrizes e Bases da Educação Nacional. Brasília, 1996.

BRASIL. Resolução CEB n. 99. Institui as Diretrizes Curriculares Nacionais para a Educação de Jovens e Adultos.

DAFT, Richard L. Organizações: teoria e projetos. São Paulo: Thomson/Fronteira, 2002.

DAVENPORT, Thomas H; PRUSAK, Laurence. Conhecimento empresarial: como as organizações gerenciam o seu capital intelectual. Rio de Janeiro: Campus, 1998.

DAVENPORT, Thomas H; PRUSAK, Laurence. Conhecimento empresarial. Rio de Janeiro: Campus; São Paulo: Publifolha, 1999.

DIBELLA, Anthony J. Como as organizações aprendem: uma estratégia integrada voltada para a construção da capacidade de aprendizagem. São Paulo: Educator, 1999.

DRUCKER, Peter Ferdinand. Desafios gerenciais para o século XXI. São Paulo: Pioneira, 1999.

FONSECA, Giovanni C. Aprendizagem, socialização e conflito no trabalho: a dimensão tácita do (des)conhecimento nas organizações. Belo Horizonte: UFMG, 2005. 113f. Dissertação (mestrado em Engenharia de Produção). Universidade Federal de Minas Gerais.

GARVIN, David A. Construindo a organização que aprende. In: Gestão do conhecimento. Harvard Business Review. Rio de Janeiro, Campus, 2000, p. 50-81.

GONSALVES, Elisa Pereira. Iniciação à pesquisa científica. Campinas: Alínea, 2001.

LAKATOS, Eva M; MARCONI, Maria de A. Fundamentos de metodologia científica. São Paulo: Atlas, 2005.

LEMOS, Cristina. Inovação na era do conhecimento. In: LASTRES, Helena M. M; ALBAGLI, Sarita (org.). Informação e globalização na era do conhecimento. Rio de Janeiro: Campus, 1999, p. 122-143.

LIBÂNEO, José Carlos. Organização e gestão da escola: teoria e prática. Goiânia: Alternativa, 2004.

OROSCO, Norma T. et al. Preservando a memória organizacional da CNEN. Disponível em 
<http://www.cinform.ufba.br7cinformsoacpapersd78556f901901fe00f4197ad4c3b.pdf>. Acesso em 30 ago. 2015.

MARTINS, Jorge Santos. O trabalho com projetos de pesquisa: do ensino fundamental ao ensino médio. Campinas: Papirus, 2004.

NONAKA, Ikujiro; TAKEUCHI, Hirotaka. Criação de conhecimento na empresa. Rio de Janeiro: Campus, 1997.

PETRASH, Gordon. Managing knowledge assets for value. In: KNOWLEDGE-BASED LEADERSHIP CONFERENCE. Boston: Linkage, 1996.

POLANYI, Karl. A grande transformação. Rio de Janeiro: Campus, 2000.

PROBST, Gilbert; RAUB, Steffen; ROMHARDT, Kai. Gestão do conhecimento: os elementos construtivos do sucesso. Porto Alegre: Bookman, 2002.

RICHARDSON, Roberto. J. Pesquisa social: métodos e técnicas. São Paulo: Atlas, 1999.

STEWART, Thomas A. A riqueza do conhecimento: o capital intelectual e a organização do Século XXI. Rio de Janeiro: Campus, 2002.

TERRA, José Cláudio C. Gestão do conhecimento: o grande desafio empresarial. São Paulo: Negócio, 2001.

ZHENG. YANG; MCLEAN. Ligando a cultura organizacional, estrutura, estratégia e eficácia organizacional: mediando papel da gestão do conhecimento. Journal of Business Research, 2010, v. 63, n 7, 2010, p. 763-771.

Antonio Amorim é professor pleno na Universidade do Estado da Bahia atuando no Programa de Mestrado Profissional em Educação de Jovens e Adultos. Doutor em Psicologia pela Universidade de Barcelona/Espanha.

Endereço: Rua Silveira Martins, 2555 - 41150-000 - Salvador - BA - Brasil.

E-mail: amorimrho25@yahoo.com.br.

Aldaíce Damasceno Rocha é professora no Centro Estadual de Educação Magalhães Netto - CEA - na Educação de Jovens e Adultos. Estudante do curso de mestrado em Letras na Universidade Federal da Bahia.

Endereço: Travessa Constâncio Alves, 184/201A - 40045-125 -Salvador - BA Brasil.

E-mail: iceroche@hotmail.com.

Alfredo Eurico da Matta é professor na Universidade do Estado da Bahia. Pósdoutor em Educação a Distância pela Universidade do Porto, doutor em Educação pela UFBA/Université Laval, Canadá. Pesquisador do CNPq.

Endereço: Rua Silveira Martins, 2555 - 41150-000 - Salvador - BA - Brasil.

E-mail: alfredo@matta.pro.br.

Recebido em 9 de janeiro de 2017.

Aceito em 13 de abril de 2017. 